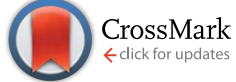

Cite this: RSC Adv., 2016, 6, 27584

Received 3rd February 2016

Accepted 6th March 2016

DOI: 10.1039/c6ra03188a

www.rsc.org/advances

\section{Open-air oxidative Mizoroki-Heck reaction of arylsulfonyl hydrazides with alkenes $\uparrow$}

\author{
On Ying Yuen, Chau Ming So* and Fuk Yee Kwong* \\ A palladium(॥)-catalyzed oxidative Mizoroki-Heck reaction of arylsulfonyl hydrazides with alkenes was \\ developed employing atmospheric air as the sole oxidant in an open-vessel manner. By using \\ palladium(॥) acetate associating with inexpensive, air-stable and moisture stable pyridine ligand L9 as the \\ catalyst system, the efficiency of the reaction could be significantly enhanced. A wide range of \\ arylsulfonyl hydrazides underwent the oxidative Mizoroki-Heck reaction with alkenes smoothly. \\ Good-to-excellent product yields and excellent regio- and stereoselectivity were achieved. Functional \\ groups such as halo, ester etc. were well-tolerated under these optimized reaction conditions.
}

\section{Introduction}

The palladium-catalyzed Mizoroki-Heck reaction is one of the most powerful tools for incorporating a $\mathrm{C}-\mathrm{C}$ double bond in organic synthesis ${ }^{\mathbf{1}}$ and plays an important role in both synthetic laboratories and industrial applications. ${ }^{2}$ In the traditional Heck reaction, aryl halides act as electrophiles and couple with alkenes in the presence of palladium catalysts under basic conditions to produce higher substituted alkenes. ${ }^{3}$ Apart from aryl halides, aryl sulfonates, ${ }^{4}$ aryl diazonium salts, ${ }^{5}$ arylsulfonyl halides, ${ }^{6}$ and arylcarboxylic acid derivatives ${ }^{7}$ are also effective aryl sources in the Mizoroki-Heck type reactions.

The oxidative Heck reaction is also an excellent pathway to access substituted alkene products. ${ }^{8}$ The most striking difference between traditional Heck reaction and oxidative Heck

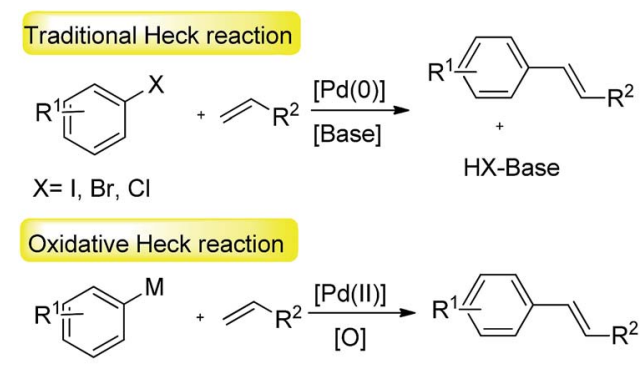

$\mathrm{M}=$ boronic acids or esters, carboxylic acids, phosphonic acids....

Scheme 1 Traditional Heck reaction of aryl halides and oxidative Heck reaction using other aryl sources with alkenes.

State Key Laboratory of Chirosciences and Department of Applied Biology and Chemical Technology, The Hong Kong Polytechnic University, Hung Hom, Kwoloon, Hong Kong, China.E-mail: chau.ming.so@polyu.edu.hk; fuk-yee.kwong@polyu.edu.hk $\dagger$ Electronic supplementary information (ESI) available. See DOI: 10.1039/c6ra03188a reaction is the reaction mechanism. The former is that electrophiles act as self-oxidant for carrying out oxidative addition to palladium(0) species to form arylpalladium(II) intermediates. The latter is that extra oxidants such as oxygen or copper(II) salts are required to re-oxidize palladium(0) species to palladium(II) complexes. Aromatics, ${ }^{9}$ arylcarboxylic acids, ${ }^{10}$ arylboronic acid derivatives, ${ }^{11}$ arylphosphonic acids,${ }^{12}$ arylsulfonic acids ${ }^{13}$ and its sodium salts, ${ }^{14}$ arylhydrazines, ${ }^{15}$ carbazates ${ }^{16}$ and aroyl hydrazides $^{17}$ were shown to effectively couple with alkenes in the oxidative reactions (Scheme 1).

Arylsulfonyl hydrazides are recently rising electrophiles which are readily accessible solids, stable in air and moisture conditions and can be easily prepared in one step from arylsulfonyl chlorides and hydrazine hydrates. ${ }^{18}$ Particular noteworthy is that they can serve as arylating agents, which are subjected to denitrogenation and desulfitation to generate the aryl source for the oxidative palladium-catalyzed coupling reactions. ${ }^{19}$ Oxidative Heck reaction, ${ }^{19 a}$ oxidative direct arylation of heteroarenes, ${ }^{\mathbf{1 9 b}-\boldsymbol{d}}$ oxidative conjugate addition reaction, ${ }^{\mathbf{1 9 e}}$ oxidative homo-coupling reaction, ${ }^{19 f}$ oxidative Suzuki reaction $^{19 g}$ and oxidative Hiyama reaction ${ }^{19 h}$ have been reported.

Currently, most of these reactions are using excess amount of $\mathrm{Cu}(\mathrm{OAc})_{2}$ or pure oxygen as oxidant. We envision that the use of the atmospheric air in open-vessel manner is one of the most attractive protocols for the oxidative Heck reaction because of the following advantages: (1) avoid the handling of dangerous and hazardous pressurized gas tube, (2) allow to release the extra gaseous pressure generates from denitrogenation $\left(\mathrm{N}_{2}\right)$ and desulfitation $\left(\mathrm{SO}_{2}\right)$ of arylsulfonyl hydrazides under high temperature, (3) can provide a constant oxygen concentration over the whole reaction period which may maximize the utility of this technology for genuine applications. However, in general, only inferior yields were obtained when air is used as the reaction atmosphere especially for the Heck-type 
Table 1 Initial screening of palladium-catalyzed oxidative MizorokiHeck-type reaction of arylsulfonyl hydrazides ${ }^{a}$

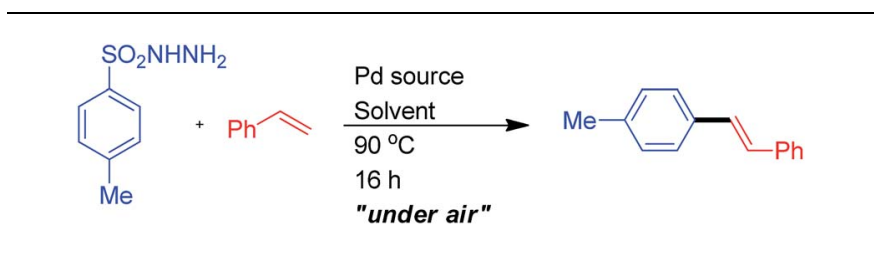

\begin{tabular}{|c|c|c|c|}
\hline Entry & Catalyst (mol\%) & Solvent & $\%$ yield $^{b}$ \\
\hline 1 & $\mathrm{Pd}(\mathrm{OAc})_{2}(10)$ & Dioxane & 40 \\
\hline 2 & $\mathrm{Pd}(\mathrm{OAc})_{2}(10)$ & $\mathrm{DMF}$ & 55 \\
\hline 3 & $\mathrm{Pd}(\mathrm{OAc})_{2}(10)$ & DMA & 47 \\
\hline 4 & $\mathrm{Pd}(\mathrm{OAc})_{2}(10)$ & NMP & 40 \\
\hline 5 & $\mathrm{Pd}(\mathrm{OAc})_{2}(10)$ & DMSO & 14 \\
\hline 6 & $\mathrm{Pd}(\mathrm{OAc})_{2}(10)$ & THF & 7 \\
\hline 7 & $\mathrm{Pd}(\mathrm{OAc})_{2}(10)$ & $t$-BuOH & 20 \\
\hline 8 & $\mathrm{Pd}(\mathrm{OAc})_{2}(10)$ & Toluene & 5 \\
\hline 9 & $\mathrm{Pd}(\mathrm{OAc})_{2}(10)$ & $\mathrm{MeCN}$ & 13 \\
\hline 10 & $\mathrm{Pd}(\mathrm{OAc})_{2}(10)$ & PhCN & 26 \\
\hline 11 & $\mathrm{Pd}(\mathrm{OAc})_{2}(10)$ & $\mathrm{AcOH}$ & 17 \\
\hline 12 & $\mathrm{Pd}_{2}(\mathrm{dba})_{3}(10)$ & DMF & 15 \\
\hline 13 & $\mathrm{Pd}\left(\mathrm{COOCF}_{3}\right)_{2}(10)$ & DMF & 41 \\
\hline 14 & $\mathrm{Pd}(\mathrm{acac})_{2}(10)$ & $\mathrm{DMF}$ & 23 \\
\hline 15 & $\mathrm{PdCl}_{2}\left(\mathrm{CH}_{3} \mathrm{CN}\right)_{2}(10)$ & DMF & 51 \\
\hline 16 & $\mathrm{PdCl}_{2}\left(\mathrm{PPh}_{3}\right)_{2}(10)$ & $\mathrm{DMF}$ & 32 \\
\hline 17 & $\mathrm{PdCl}_{2}(\mathrm{COD})_{2}(10)$ & $\mathrm{DMF}$ & Trace \\
\hline 18 & $\mathrm{PdCl}_{2}(10)$ & DMF & 40 \\
\hline
\end{tabular}

${ }^{a}$ Reaction condition: 4-methylbenzenesulfonyl hydrazide $(0.45 \mathrm{mmol})$, styrene $(0.3 \mathrm{mmol})$, Pd source $(10 \mathrm{~mol} \%)$ and solvent $(3.0 \mathrm{~mL})$ were stirred at $90{ }^{\circ} \mathrm{C}$ for $16 \mathrm{~h}$ under air. ${ }^{b}$ Calibrated GC yields were reported using dodecane as internal standard.

reactions. ${ }^{19 a, e}$ Herein, we attempted to advance this oxidative Heck reaction by using atmospheric air in open air manner.

\section{Results and discussion}

In order to test the feasibility of palladium-catalyzed oxidative Mizoroki-Heck reaction of arylsulfonyl hydrazides with alkenes, a series of screenings was conducted (Table 1). 4-Methylbenzenesulfonyl hydrazide and styrene were used as the benchmark substrates. In surveying of common solvents, DMF gave the best result (Table 1 , entry 2 and entries 1-11). The initial screening of palladium sources (Table 1, entries 12-18) indicated that $\mathrm{Pd}(\mathrm{OAc})_{2}$ was the suitable Pd source for this coupling reaction.

After the detailed optimization of solvents and Pd sources, we still found that the product yield was unsatisfactory. Inspired by the poor result of $\mathrm{Pd}(\mathrm{OAc})_{2} / \mathrm{DMSO}$ system which is one of the well-known catalyst systems for the palladium-catalyzed oxidative reactions and also analogy to the aerobic alcohol oxidation reaction and oxidative amination of olefins reaction, ${ }^{20}$ we were intrigued that the inferior yield may result from the slow aerobic oxidation of $\operatorname{Pd}(0)$ species to $\operatorname{Pd}(\mathrm{II})$, especially under air atmosphere which is low oxygen concentration. $\operatorname{Pd}(0)$ species easily aggregate and agglomerate to unreactive palladium black and retard the coupling catalysis in the ligand-free Heck reactions. Oxidatively stable ligands have been identified to enhance the rate of $\operatorname{Pd}(0)$
Table 2 Ligand screening for palladium-catalyzed oxidative Mizoroki-Heck-type reaction of arylsulfonyl hydrazides ${ }^{a, b}$

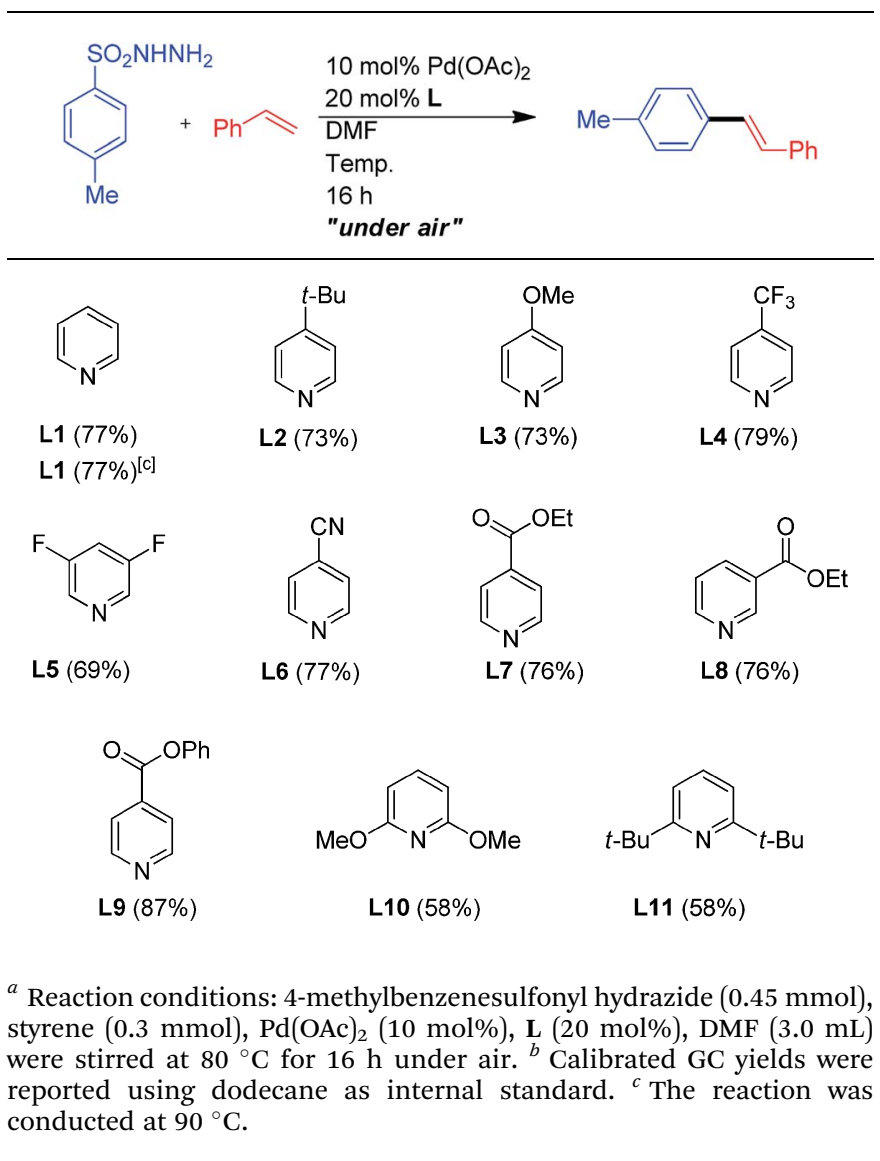

oxidation particularly with respect to competing $\operatorname{Pd}(0)$ aggregation so as to promote catalyst turnover, improve catalyst stability and increases regio- and stereoselectivity of the reaction. ${ }^{20}$

Uemura's $\mathrm{Pd}(\mathrm{OAc})_{2}$ /pyridine catalyst system were found to promote the oxidation of $\operatorname{Pd}(0)$ to $\operatorname{Pd}($ II) in the aerobic alcohol oxidation reaction. ${ }^{20}$ Herein, we adopt the $\mathrm{Pd}(\mathrm{OAc})_{2}$ /pyridine catalyst system for the oxidative Heck reaction of arylsulfonyl hydrazides with alkenes for the first time.

We found that when pyridine was added, the product yield improved satisfactorily from $55 \%$ to $77 \%$ (Table 2, L1). When the reaction temperature was lowered from $90{ }^{\circ} \mathrm{C}$ to $80^{\circ} \mathrm{C}$, the product yield remained the unaffected. An evaluation of different substituted pyridine ligands L2-L11 indicated that phenyl isonicotinate (L9) gave the best yield of product. Although the electronic influence of the pyridine-type ligands in this oxidative heck reaction is still unclear, sterically hindered pyridine type ligands L10-L11 which hinder the facial coordination to Pd center show minor enhancing effect of the product yield that imply the importance of the ligand coordination effect.

With the $\mathrm{Pd}(\mathrm{OAc})_{2} / \mathbf{L 9}$ system in hand, we next investigated the scope of Mizoroki-Heck reaction of arylsulfonyl hydrazides with alkenes. The results were summarized in Table 3. A wide range of arylsulfonylhydrazides carried out oxidative Mizoroki-Heck reaction with styrene smoothly to give 1,2-disubstituted alkenes in moderate-to-excellent yields under air 
Table 3 Palladium-catalyzed oxidative Mizoroki-Heck-type reaction of arylsulfonyl hydrazides and olefins ${ }^{a, b}$

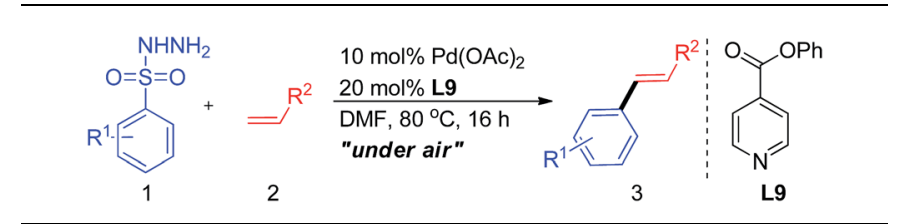

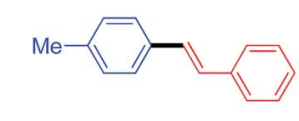

3ak $87 \%$

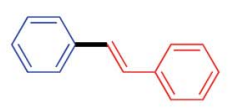

$3 \mathrm{dk} 84 \%$

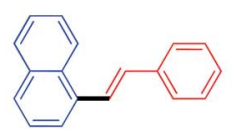

3gk $75 \%$

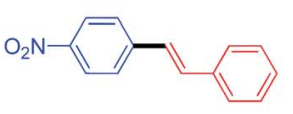

$3 j k 41 \%$ [d]

3an $84 \%$

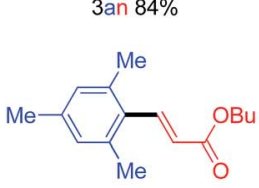

3in $81 \%[c]$

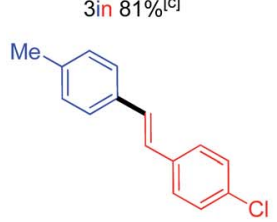

3aq $79 \%$

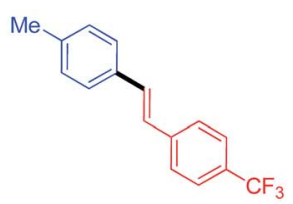

3at $76 \%$

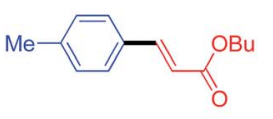

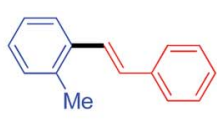

3bk $90 \%$
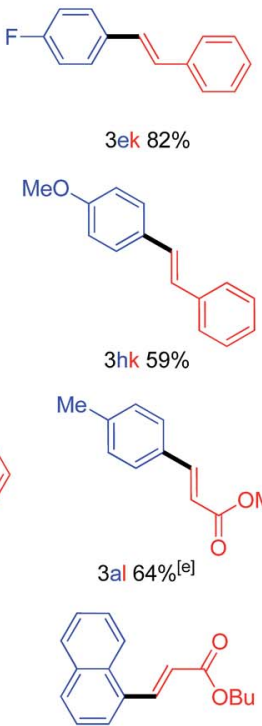

3gn $95 \%$
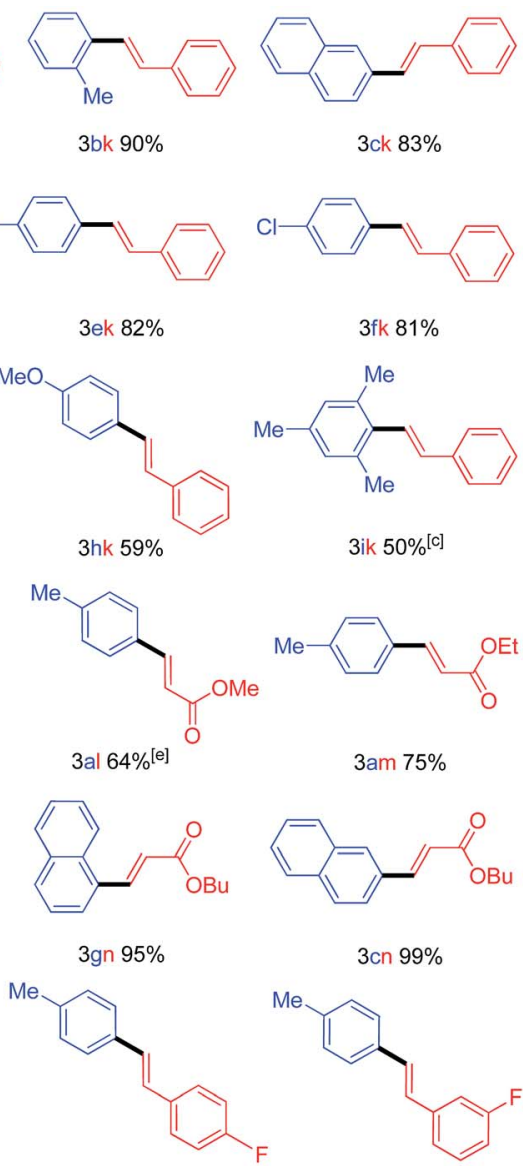

3ck $83 \%$
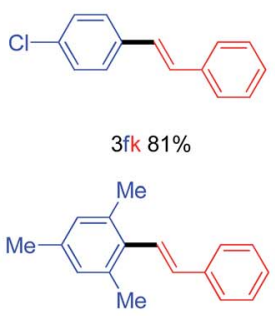

3 ik $50 \%$ [c]
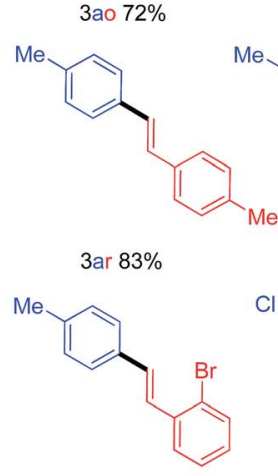

3au $50 \%[f]$

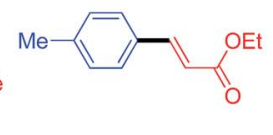

3am $75 \%$

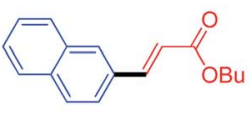

$3 \mathrm{cn} 99 \%$

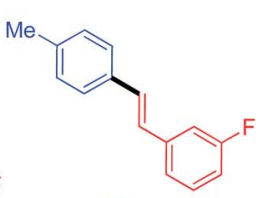

3 ap $77 \%$

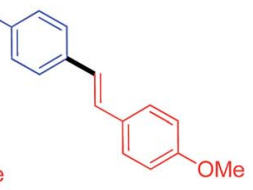

3 as $68 \%$

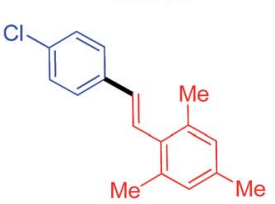

$3 f v 69 \%[f]$
${ }^{a}$ Reaction conditions: arylsulfonyl hydrazide $(0.45 \mathrm{mmol})$, alkene $(0.3$ $\mathrm{mmol}), \mathrm{Pd}(\mathrm{OAc})_{2}(10 \mathrm{~mol} \%), \mathbf{L 9}(20 \mathrm{~mol} \%)$ and DMF $(3 \mathrm{~mL})$ were stirred at $80{ }^{\circ} \mathrm{C}$ for $16 \mathrm{~h}$ under air. ${ }^{b}$ Isolated yield. ${ }^{c}$ The reaction was conducted at $70{ }^{\circ} \mathrm{C}$. ${ }^{d}$ The reaction was conducted at $100{ }^{\circ} \mathrm{C}$. ${ }^{e}$ Close system was used. ${ }^{f}$ The reaction was conducted for $24 \mathrm{~h}$. atmosphere. ortho-Substituted arylsulfonyl hydrazides were good coupling partners for this reaction (Table 3, compounds 3bk and 3gk). Electron-rich arylsulfonyl hydrazide afforded moderate yield (Table 3 , compound $\mathbf{3 h k}$ ). The highly sterically hindered arylsulfonyl hydrazide coupled well with styrene (Table 3, compound 3ik). Apart from styrene, a variety of substituted styrenes and acrylates was examined and provided good to excellent product yields. ${ }^{21}$ To our delight, the highly sterically hindered arylsulfonyl hydrazide coupled with butyl acrylate in good yield (Table 3, compound 3in). Both of electrondeficient and electron-rich substituents on styrenes were feasible cross-coupling partners (Table 3, compounds 3ao, 3ap, 3aq, 3as, 3at and 3au). The highly sterically crowded 2,4,6-trimethylstyrenes proceeded well with 4-chlorobenzenesulfonyl hydrazide partner smoothly (Table 3, compound 3fv). Notably, bromo and chloro groups were compatible under these optimized reaction conditions that are useful moieties for further chemical transformations using other coupling technology (Table 3 , compounds $3 \mathbf{f k}$, 3aq, 3au and $3 \mathbf{f v}$ ).

In order to have a better understanding of the effect of pyridine ligand towards the reaction rate of palladium-catalyzed oxidative Mizoroki-Heck reaction, 4-methylbenzenesulfonyl hydrazide and styrene were selected as substrates for the kinetic studies (Scheme 2). Two sets of parallel experiment in the presence of $\mathbf{L} \mathbf{9}$ and absence of $\mathbf{L} \mathbf{9}$ were conducted which was represented by $\mathbf{~}$ blue line and $\bullet$ red line in Scheme 2 respectively. The reaction rates in both cases were essentially the same within the first $30 \mathrm{~min}$, which indicated the reaction rate was not obviously promoted by the presence of L9. At $45 \mathrm{~min}$, on the wall of the reaction tube, a small amount of palladium black was observed in the absence of $\mathbf{L 9}$ while palladium black was not observed in the presence of $\mathbf{L 9}$. In the absence of the $\mathbf{L 9}$, the reaction rate decreased more significantly at $90 \mathrm{~min}$ and the reaction rate became steady after 180 $\mathbf{m i n}$. In contrast, in the presence of $\mathbf{L} \mathbf{9}$, the reaction rate decreased relatively slower in the first $120 \mathrm{~min}$ and the reaction rate became steady after $240 \mathrm{~min}$. Furthermore, in the presence of the $\mathbf{L} \mathbf{9}$, a higher turnover number could be obtained within the same reaction period. This kinetic result implied that the coordination of the pyridine ligand to the Pd center may reduce the possibility of the formation of inactive Pd black so that the reaction can be promoted by a higher concentration of the active Pd species during the course of the reaction.

A proposed catalytic cycle, as adapted from the mechanistic studies performed on the Pd-catalyzed coupling reactions of arylsulfonyl hydrazides and $\mathrm{Pd}(\mathrm{OAc})_{2} /$ pyridine oxidation reaction mechanism, is shown in Scheme 3.19,20 The coordination of the pyridine ligand to $\mathrm{Pd}(\mathrm{OAc})_{2}$ generate complex I which is subsequently converted to complex II and HOAc by deprotonation with arylsulfonyl hydrazide. Complex II undergoes $\beta$-hydride elimination to give complex III and sulfonyl diazene. Displacement of complex I with sulfonyl diazene gives complex IV. Liberation of $\mathrm{N}_{2}$ with complex IV provides the complex $\mathbf{V}$, and successive extrusion of $\mathrm{SO}_{2}$ affords complex VI. The coordination of alkene to complex VI followed by alkene insertion generates complex VII. Complex VII undergoes $\beta$-hydride elimination to generate complex III. Reductive elimination of complex III generates complex VIII, and the complex $\mathbf{I}$ is regenerated by oxidation. 


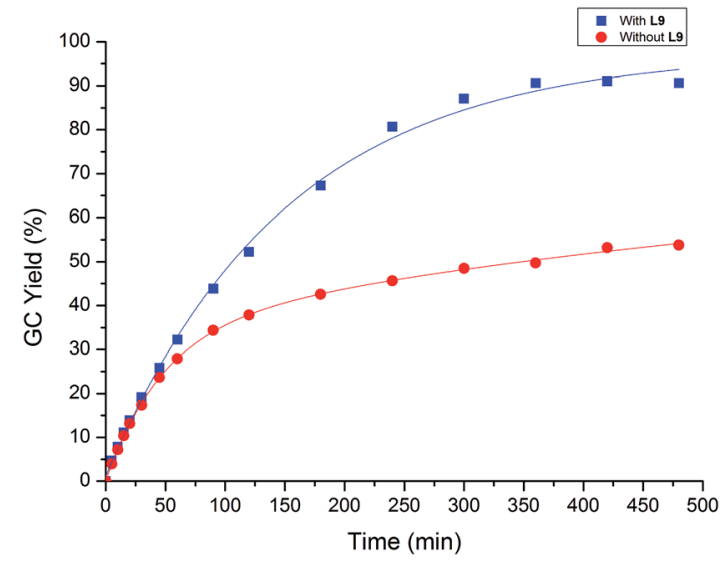

Scheme 2 Kinetic study of the effect of the pyridine ligand L9 on the oxidative Mizoroki-Heck-type reaction of 4-methylbenzenesulfonyl hydrazide with styrene.

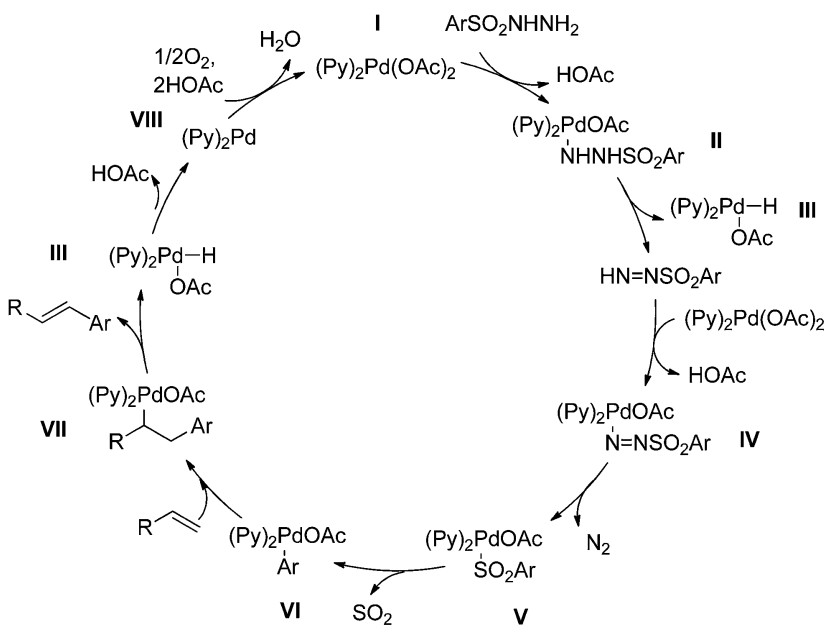

Scheme 3 Proposed catalytic cycle.

\section{Conclusions}

In summary, we have reported the first examples of oxidative Mizoroki-Heck reaction of arylsulfonyl hydrazides with alkenes in an open-air manner using the stable and inexpensive pyridine ligand L9. The $\operatorname{Pd}(\mathrm{OAc})_{2} / \mathbf{L} \mathbf{9}$ catalyst system was effective for the coupling of a wide range of arylsulfonyl hydrazides and alkenes. It was noteworthy that the reaction was conducted under atmospheric air. The preliminary kinetic study result showed that pyridine ligand $\mathbf{L 9}$ may reduce the $\operatorname{Pd}(0)$ aggregation so as to promote catalyst turnover. We expect this convenient synthetic method will be useful in the organic synthesis.

\section{Experimental section}

\section{General procedure for the oxidative heck reaction of arylsulfonyl hydrazides with alkenes}

All reagents were weighted in air and the reactions were performed in an open vessel. $\mathrm{Pd}(\mathrm{OAc})_{2}(0.0068 \mathrm{~g}, 0.03 \mathrm{mmol})$ and phenyl isonicotinate $(\mathrm{Pd}: \mathbf{L}=1: 2)$ were loaded into a $40 \mathrm{~mL}$ vial equipped with a Teflon-coated magnetic stir bar. Precomplexation was applied by adding DMF ( $1 \mathrm{~mL})$ in to the vial. The palladium complex stock solution was stirred for 10 minutes. Arylsulfonyl hydrazide $(0.45 \mathrm{mmol})$ and alkenes $(0.3 \mathrm{mmol})$ were loaded into the vial. DMF ( $2 \mathrm{~mL}$ ) was added with continuous stirring at room temperature. The vial was fitted with an air condenser as cooler and then placed into a preheated oil bath which the temperature was indicated in the table and vigorously stirred for $16 \mathrm{~h}$. After the completion of reaction, the reaction vial was allowed to cool at room temperature. Ethyl acetate $(\sim 10 \mathrm{~mL})$ was added. The organic layer was subjected to GC analysis. After analyzing GC spectra, the crude product in the organic layer was extracted and the vial washed with ethyl acetate. The filtrate was concentrated under reduced pressure. The crude product was purified by flash column chromatography on silica gel (230-400 mesh) to afford the desired product.

\section{Acknowledgements}

We thank the Research Grants Council of Hong Kong, (CRF: C5023-14G), and General Research Fund (GRF: PolyU 153008/14P) and State Key Laboratory of Chirosciences for financial support. Grateful to Prof. Albert S. C. Chan's research group (PolyU Hong Kong) for sharing of GC-FID and GC-MS instruments.

\section{Notes and references}

1 (a) R. F. Heck, Acc. Chem. Res., 1979, 12, 146; (b) G. D. Daves Jr and A. Hallberg, Chem. Rev., 1989, 89, 1433; (c) W. Cabri and I. Candiani, Acc. Chem. Res., 1995, 28, 2; (d) G. T. Crisp, Chem. Soc. Rev., 1998, 27, 427; (e) I. P. Beletskaya and A. V. Cheprakov, Chem. Rev., 2000, 100, 3009; (f) A. F. Littke and G. C. Fu, Angew. Chem., Int. Ed., 2002, 41, 4176.

2 N. J. Lawrence, in Preparation of Alkenes: a Practical Approach, ed. J. M. J. Williams, Oxford University Press, Oxford, UK, 1995.

3 (a) T. Mizoroki, K. Mori and A. Ozaki, Bull. Chem. Soc. Jpn., 1971, 44, 581; (b) R. F. Heck and J. P. Nolley, J. Org. Chem., 1972, 37, 2320; (c) X.-F. Wu, P. Anbarasan, H. Neumann and M. Beller, Angew. Chem., Int. Ed., 2010, 49, 9047.

4 (a) Q.-Y. Chen and Z.-Y. Yang, Tetrahedron Lett., 1986, 27, 1171; (b) T. M. Gøgsig, A. T. Lindhardt, M. Dekhane, J. Grouleff and T. Skrydstrup, Chem.-Eur. J., 2009, 15, 5950. 5 For reviews, see: (a) J. G. Taylor, A. M. Moro and C. R. D. Correia, Eur. J. Org. Chem., 2011, 1403; (b) A. Roglans, A. Pla-Quintana and M. Moreno-Maňas, Chem. Rev., 2006, 106, 4622. For recent examples, see: (c) F. Le Callonnec, E. Fouquet and F.-X. Felpin, Org. Lett., 2011, 13, 2646; (d) E. W. Werner and M. S. Sigman, J. Am. Chem. Soc., 2011, 133, 9692.

6 (a) M. Miura, H. Hashimoto, K. Itoh and M. Nomura, Tetrahedron Lett., 1989, 30, 975; (b) S. R. Dubbaka and P. Vogel, Chem.-Eur. J., 2005, 11, 2633.

7 (a) C.-M. Andersson and A. Hallberg, J. Org. Chem., 1988, 53, 235; (b) M. S. Stephan, A. J. J. M. Teunissen, G. K. M. Verzijl and J. G. de Vries, Angew. Chem., Int. Ed., 1998, 37, 662; (c) 
L. J. Gooßen, J. Paetzold and L. Winkel, Synlett, 2002, 1721; (d) L. J. Gooßen and J. Paetzold, Angew. Chem., Int. Ed., 2002, 41, 1237; (e) L. J. Gooßen and J. Paetzold, Angew. Chem., Int. Ed., 2004, 43, 1095; ( $f$ ) T. Sugihara, T. Satoh and M. Miura, Tetrahedron Lett., 2005, 46, 8269.

8 For reviews, see: (a) B. Karimi, H. Behzadnia, D. Elhamifar, P. F. Akhavan, F. K. Esfahani and A. Zamani, Synthesis, 2010, 1399; (b) R. Rossi, F. Bellina and M. Lessi, Synthesis, 2010, 4131; (c) J. Le Bras and J. Muzart, Chem. Rev., 2011, 111, 1170.

9 For reviews, see: (a) J. Le Bras and J. Muzart, Chem. Rev., 2011, 111, 1170; (b) C. Jia, T. Kitamura and Y. Fujiwara, Acc. Chem. Res., 2001, 34, 633; (c) I. Moritani and Y. Fujiwara, Synthesis, 1973, 524. For recent examples, see: (d) K. M. Engle, D.-H. Wang and J.-Q. Yu, Angew. Chem., Int. Ed., 2010, 49, 6169; (e) Y. Lu, D.-H. Wang, K. M. Engle and J.-Q. Yu, J. Am. Chem. Soc., 2010, 132, 5916; $(f)$ K. M. Engle, D.-H. Wang and J.-Q. Yu, J. Am. Chem. Soc., 2010, 132, 14137; (g) D.-H. Wang, K. M. Engle, B.-F. Shi and J.-Q. Yu, Science, 2010, 327, 315; (h) M. Ye, G.-L. Gao and J.-Q. Yu, J. Am. Chem. Soc., 2011, 133, 6964; (i) T. Nishikata and B. H. Lipshutz, Org. Lett., 2010, 12, 1972; (j) H.-X. Dai, A. F. Stepan, M. S. Plummer, Y.-H. Zhang and J.-Q. Yu, J. Am. Chem. Soc., 2011, 133, 7222; (k) C. Huang, B. Chattopadhyay and V. Gevorgyan, J. Am. Chem. Soc., 2011, 133, 12406; (l) S. Cui, L. Wojtas and J. C. Antilla, Org. Lett., 2011, 13, 5040; $(m)$ M. Yu, Z. Liang, Y. Wang and Y. Zhang, J. Org. Chem., 2011, 76, 4987; $(n)$ X. Liu and K. K. Hii, J. Org. Chem., 2011, 76, 8022; (o) A. García-Rubia, M. A. Fernández-Ibáñez, R. G. Arrayás and J. C. Carretero, Chem.-Eur. J., 2011, 17, 3567; (p) A. García-Rubia, B. Urones, R. G. Arrayás and J. C. Carretero, Angew. Chem., Int. Ed., 2011, 50, 10927.

10 (a) A. G. Myers, D. Tanaka and M. R. Mannion, J. Am. Chem. Soc., 2002, 124, 11250; (b) D. Tanaka and A. G. Myers, Org. Lett., 2004, 6, 433; (c) D. Tanaka, S. P. Romeril and A. G. Myers, J. Am. Chem. Soc., 2005, 127, 10323; (d) P. Hu, J. Kan, W. Su and M. Hong, Org. Lett., 2009, 11, 2341; (e) S.-L. Zhang, Y. Fu, R. Shang, Q.-X. Guo and L. Liu, J. Am. Chem. Soc., 2010, 132, 638; (f) Z. Fu, S. Huang, W. Su and M. Hong, Org. Lett., 2010, 12, 4992.

11 For selected references: $(a)$ C. S. Cho and S. Uemura, J. Organomet. Chem., 1994, 465, 85; (b) X. Du, M. Suguro, K. Hirabayashi and A. Mori, Org. Lett., 2001, 3, 3313; (c) Y. C. Jung, R. K. Mishra, C. H. Yoon and K. W. Jung, Org. Lett., 2003, 5, 2231; (d) M. M. S. Andappan, P. Nilsson and M. Larhed, Chem. Commun., 2004, 218; (e) K. S. Yoo, C. H. Yoon and K. W. Jung, J. Am. Chem. Soc., 2006, 128, 16384; (f) J. Ruan, X. Li, O. Saidi and J. Xiao, J. Am. Chem. Soc., 2008, 130, 2424; (g) J. Limdh, J. Sävmarker, P. Nilsson, P. J. R. Sjçberg and M. Larhed, Chem.-Eur. J., 2009, 15, 4630; (h) Y. Leng, F. Yang, K. Wei and Y. Wu, Tetrahedron, 2010, 66, 1244; (i) E. W. Werner and M. S. Sigman, J. Am. Chem. Soc., 2010, 132, 13981; (j) Y. Liu, D. Li and C.-M. Park, Angew. Chem., Int. Ed., 2011, 50, 7333; $(k)$ A. L. Gottumukkala, J. F. Teichert, D. Heijneen, N. Eeisink, S. V. Dijk, C. Ferrer,
A. V. D. Hoogenband and A. J. Minnaard, J. Org. Chem., 2011, 76, 3498; (l) M. Khoobi, M. Alipour, S. Zareei, F. Jafarpour and A. Shafiee, Chem. Commun., 2012, 48, 2985; $(m)$ Z. He, S. Kirchberg, R. Fröhlich and A. Studer, Angew. Chem., Int. Ed., 2012, 51, 3699; (n) L. Zhang, C. Dong, C. Ding, J. Chen, W. Tang, H. Li, L. Xu and J. Xiao, Adv. Synth. Catal., 2013, 355, 1570; (o) L. Meng, C. Liu, W. Zhang, C. Zhou and A. Lei, Chem. Commun., 2014, 50, 1110; (p) J. Zheng, L. Huang, C. Huang, W. Wu and H. Jiang, J. Org. Chem., 2015, 80, 1235.

12 A. Inoue, H. Shinokubo and K. Oshima, J. Am. Chem. Soc., 2003, 125, 1484.

13 (a) K. Garves, J. Org. Chem., 1970, 35, 3273; (b) G.-W. Wang and T. Miao, Chem.-Eur. J., 2011, 17, 5787.

14 X. Zhou, J. Luo, J. Liu, S. Peng and G.-J. Deng, Org. Lett., 2011, 13, 1432.

15 M.-K. Zhu, J.-F. Zhao and T.-P. Loh, Org. Lett., 2011, 13, 6308. 16 Y.-H. Su, Z. Wu and S.-K. Tian, Chem. Commun., 2013, 49, 6528.

17 Y.-G. Zhang, X.-L. Liu, Z.-Y. He, X.-M. Li, H.-J. Kang and S.-K. Tian, Chem.-Eur. J., 2014, 20, 2765.

18 (a) T. Taniguchi, A. Idota and H. Ishibashi, Org. Biomol. Chem., 2011, 9, 3151; (b) X. Li, X. Xu and C. Zhou, Chem. Commun., 2012, 48, 12240; (c) F.-L. Yang, X.-T. Ma and S.-K. Tian, Chem.-Eur. J., 2012, 18, 1582; (d) R. Singh, D. S. Raghuvanshi and K. N. Singh, Org. Lett., 2013, 15, 4202; (e) F.-L. Yang and S.-K. Tian, Angew. Chem., Int. Ed., 2013, 52, 4929; (f) N. Singh, R. Singh, D. S. Raghuvanshi and K. N. Singh, Org. Lett., 2013, 15, 5874; $(g)$ W. Wei, C. Liu, D. Yang, J. Wen, J. You, Y. Suo and H. Wang, Chem. Commun., 2013, 49, 10239; (h) X. Li, X. Xu, P. Hu, X. Xiao and C. Zhou, J. Org. Chem., 2013, 78, 7343; (i) X. Li, X. Xu and Y. Tang, Org. Biomol. Chem., 2013, 11, 1739; (j) S.-R. Guo, W.-M. He, J.-N. Xiang and Y.-Q. Yuan, Chem. Commun., 2014, 50, 8578; (k) T.-T. Wang, F.-X. Wang, F.-L. Yang and S.-K. Tian, Chem. Commun., 2014, 50, 3802; (l) F.-L. Yang, F.-X. Wang, T.-T. Wang, Y.-J. Wang and S.-K. Tian, Chem. Commun., 2014, 50, 2111; $(m)$ X. Kang, R. Yan, G. Yu, X. Pang, X. Liu, X. Li and L. Xiang, J. Org. Chem., 2014, 79, 10605; (n) X. Zhao, L. Zhang, T. Li, G. Liu, H. Wang and K. Lu, Chem. Commun., 2014, 50, 13121; (o) Y. Yang, L. Tang, S. Zhang, X. Guo, Z. Zha and Z. Wang, Green Chem., 2014, 16, 4106; (p) Q. Tian, P. He and C. Kuang, Org. Biomol. Chem., 2014, 12, 6349; (q) X. Li, Y. Xu, W. Wu, C. Jiang, C. Qi and H. Jiang, Chem.-Eur. J., 2014, 20, 7911; (r) S. Tang, Y. Wu, W. Liao, R. Bai, C. Liu and A. Lei, Chem. Commun., 2014, 50, 4496; $(s)$ X. Li, X. Shi, M. Fang and X. Xu, J. Org. Chem., 2013, 78, 9499; $(t)$ W. Zhang, K. Li and B. Zhao, J. Chem. Res., 2014, 38, 269; (u) J. Wang, C. Xu, S. Wei, B. Zhao and K. Cheng, Chin. J. Org. Chem., 2014, 34, 767.

19 (a) F.-L. Yang, X.-T. Ma and S.-K. Tian, Chem.-Eur. J., 2012, 18, 1582; (b) B. Liu, J. Li, F. Song and J. You, Chem.-Eur. J., 2012, 18, 10830; (c) X. Yu, X. Li and B. Wan, Org. Biomol. Chem., 2012, 10, 7479; (d) O. Y. Yuen, C. M. So, W. T. Wong and F. Y. Kwong, Synlett, 2012, 23, 2714; (e) W. Chen, H. Chen, F. Xiao and G.-J. Deng, Org. Biomol. 
Chem., 2013, 11, 4295; (f) W. Zhang, B. Zhao and K. Li, $J$. Chem. Res., 2013, 37, 674; (g) H. Miao, F. Wang, S. Zhou, G. Zhang and Y. Li, Org. Biomol. Chem., 2015, 13, 4647; $(h)$ S. Zhong, C. Sun, S. Dou and W. Liu, $R S C A d v$., 2015, 5, 27029.

20 For oxidation of reduced palladium by molecular oxygen is the rate limiting step for the $\mathrm{Pd}(\mathrm{OAc})_{2} / \mathrm{DMSO}$ system catalyzed oxidative amination of olefins, see: (a) S. R. Fix, J. L. Brice and S. S. Stahl, Angew. Chem., Int. Ed., 2002, 41, 164; for $\mathrm{Pd}(\mathrm{OAc})_{2} /$ pyridine catalyst for aerobic alcohol oxidation, see: (b) B. A. Steinhoff and S. S. Stahl, Org. Lett.,
2002, 4, 4179; (c) B. A. Steinhoff, S. R. Fix and S. S. Stahl, J. Am. Chem. Soc., 2002, 124, 766; (d) B. A. Steinhoff, L. A. Guzei and S. S. Stahl, J. Am. Chem. Soc., 2004, 126, 11268, and reference therein.

21 Only poor to fair yields could be observed when nonterminal and aliphatic alkenes were used as substrates in this oxidative Heck reaction. The isolation of the desired products from the complicated reaction mixtures containing the homo-coupling by-products and the regioisomers were unsuccessful. 